\title{
Ethnic differences in mortality from cardiovascular disease in the UK: do they persist in people with diabetes?
}

\author{
Nish Chaturvedi, John H Fuller
}

\begin{abstract}
Study objective - To determine whether ethnic differences in cardiovascular disease mortality persist in people with noninsulin-dependent diabetes mellitus.

Design - This was an ecological study in which routine mortality data from $1985-86$, which coded all mentioned causes of death, provided the numerator. The UK population derived from 1981 census formed the denominator.

Setting - United Kingdom.

Participants - Records of all deaths in people aged 45 years and above were extracted if diabetes was mentioned anywhere on the death certificate. The denominator was aged five years to approximate to the 1986 population. Mortality rates where a cardiovascular underlying cause was given were compared between South Asians, African-Caribbeans, and those born in England and Wales. The latter group formed the standard for directly standardised rate ratios. Main results - Mortality from heart disease was approximately three times higher in diabetic South Asian born men and women than in those with diabetes born in England and Wales. This ethnic difference was greatest in the younger age group. Conversely, stroke mortality rates in African-Caribbeans were $3 \cdot 5-4$ times higher than those in the England and Wales population. Despite this high mortality from stroke, ischaemic heart disease death rates were not high in African-Caribbean men. Conclusions - Ethnic differences in cardiovascular mortality persisted and were greater in those with diabetes. Thus the high risk of heart disease should be targeted for intervention in South Asians, and the high rates of stroke targeted in African-Caribbeans.
\end{abstract}

(f Epidemiol Community Health 1996;50:137-139)

Department of Epidemiology and Public Health, University College London,

1-19 Torrington Place, London WC1E 6EA

N Chaturvedi

$\mathrm{J}$ H Fuller

Correspondence to: Dr N Chaturvedi.

Accepted for publication December 1995
Deaths from cardiovascular disease (CVD) are two to three times higher in people with noninsulin-dependent diabetes mellitus (NIDDM) than in the general population, ${ }^{1-3}$ so that CVD is the main cause of premature death in people with NIDDM. The reduction of this high risk is therefore a prime therapeutic goal. ${ }^{4}$ The reasons for this increased risk are unclear, however, and constrain efforts to provide effective interventions. ${ }^{3-56}$
The observation that women with NIDDM lose their relative protection from CVD has provided valuable insights into the relationship between CVD and NIDDM, ${ }^{7}$ and helps support the hypothesis that insulin resistance and its effects on lipid homeostasis may be the key to understanding the high rates of CVD in diabetes. ${ }^{8-10}$

There are also clear ethnic differences in mortality from CVD in the general population, ${ }^{11}$ and differences in insulin resistance. ${ }^{1213}$ People from minority ethnic groups in the UK (predominantly South Asian and African-Caribbean) have diabetes rates that are three to four times that of the general population, ${ }^{1213}$ but the mortality experience from CVD in these two ethnic groups is very different. South Asian men and women have twice the mortality from CVD than the general population, and much of this is due to the high rates of heart disease. ${ }^{11}$ However, mortality from ischaemic heart disease in African-Caribbeans is only half that of the general population, despite a twofold increase in mortality from stroke. ${ }^{11}$

Examination of CVD mortality in people with NIDDM in relation to ethnicity may further help in understanding the relationship between CVD and diabetes. This would also provide valuable practical indicators of which subgroups should be targeted with specifically designed interventions.

\section{Methods}

Routine mortality data provide statistics for underlying cause of death only; they are not particularly helpful for diabetes, where the underlying cause of death is rarely diabetes itself. ${ }^{14}$ We used mortality data from 1985-86 for England and Wales, when all conditions mentioned on the death certificate were routinely recorded. All certificates where diabetes (ICD9 code 250) was mentioned for people aged 45 and above were extracted. This age cut-off was used to ensure that only people with NIDDM would be included in the sample.

Ethnicity is not routinely recorded on death certificates. However, place of birth is available, and was used as a proxy for ethnicity. "South Asian" included those born in India, Pakistan, Bangladesh, and Sri Lanka and "African-Caribbean" included all those born in the Caribbean islands. Age specific mortality rates in relation to ethnicity were calculated for the underlying cause of death when diabetes was mentioned anywhere on the death certificate. Underlying causes of death analysed were: all causes, cardiovascular disease (ICD9 
Table 1 Directly standardised rate ratios (DSRRs) (95\% confidence intervals) for all cause and cardiovascular mortality in people with diabetes comparing South Asians and African-Caribbeans with people born in England and Wales

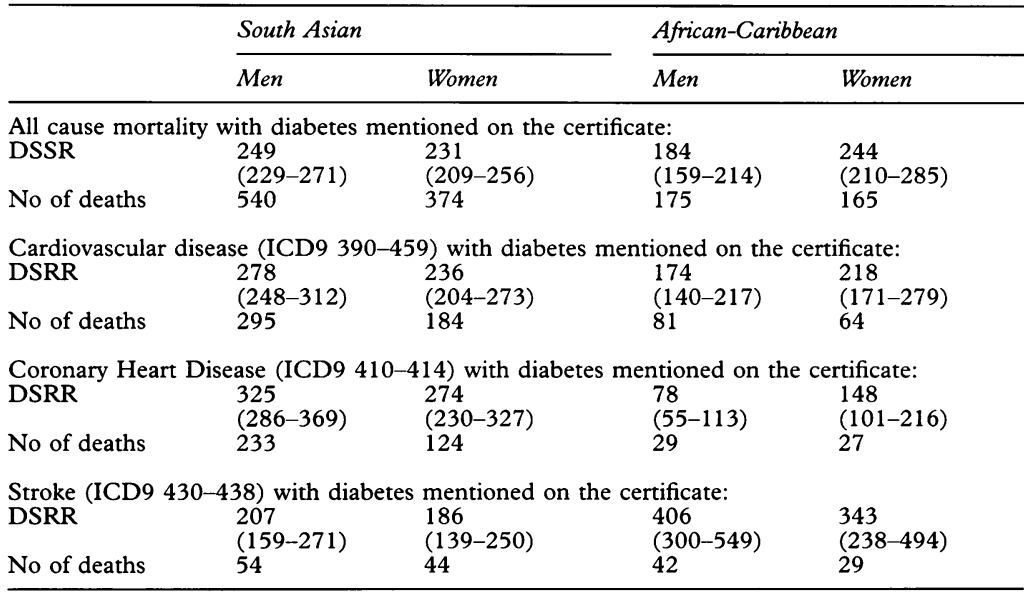

* People born in England and Wales form the standard population; DSRRs for all above conditions for England and Wales are 100.

Table 2 Relative mortality rates from all cause and cardiovascular disease in people with diabetes comparing South Asians and African-Caribbeans with people born in England and Wales (number of deaths in brackets)

\begin{tabular}{|c|c|c|c|c|}
\hline & \multicolumn{2}{|l|}{ South Asian } & \multicolumn{2}{|c|}{ African-Caribbean } \\
\hline & Men & Women & Men & Women \\
\hline $\begin{array}{l}\text { All cause mortality: } \\
45-64 \text { years } \\
(95 \% \text { CI }) \\
65+\text { years } \\
(95 \% \text { CI })\end{array}$ & $\begin{array}{l}3 \cdot 9 * * *(278) \\
(3 \cdot 4,4 \cdot 4) \\
2 \cdot 2 * * *(262) \\
(2 \cdot 0,2 \cdot 5)\end{array}$ & $\begin{array}{l}3 \cdot 8 * * *(127) \\
(3 \cdot 2,4 \cdot 6) \\
2 \cdot 2 * * *(247) \\
(1 \cdot 9,2 \cdot 4)\end{array}$ & $\begin{array}{l}1 \cdot 9 * * *(85) \\
(1 \cdot 5,2 \cdot 4) \\
1 \cdot 8 * * *(90) \\
(1 \cdot 5,2 \cdot 2)\end{array}$ & $\begin{array}{l}2 \cdot 9 * *(75) \\
(2 \cdot 3,3 \cdot 7) \\
2 \cdot 4 * * *(90) \\
(1 \cdot 9,2 \cdot 9)\end{array}$ \\
\hline $\begin{array}{l}\text { Cardiovascular disea } \\
45-64 \text { years } \\
(95 \% \mathrm{CI}) \\
65+\text { years } \\
(95 \% \mathrm{CI})\end{array}$ & $\begin{array}{l}\text { se (ICD9 390- } \\
4 \cdot 1^{* * *}(155) \\
(3 \cdot 4,4 \cdot 8) \\
2 \cdot 5^{* * *}(140) \\
(2 \cdot 1,2 \cdot 9)\end{array}$ & $\begin{array}{l}9): \\
3 \cdot 9 * * *(62) \\
(3 \cdot 0,5 \cdot 0) \\
2 \cdot 2 * * *(122) \\
(1 \cdot 8,2 \cdot 6)\end{array}$ & $\begin{array}{l}1 \cdot 7 * * *(40) \\
(1 \cdot 2,2 \cdot 3) \\
1 \cdot 8 * * *(41) \\
(1 \cdot 3,2 \cdot 4)\end{array}$ & $\begin{array}{l}1 \cdot 9 * *(24) \\
(1 \cdot 3,2 \cdot 9) \\
2 \cdot 2 * * *(40) \\
(1 \cdot 6,3 \cdot 0)\end{array}$ \\
\hline $\begin{array}{l}\text { Coronary heart dise } \\
45-64 \text { years } \\
(95 \% \text { CI }) \\
65+\text { years } \\
(95 \% \text { CI })\end{array}$ & $\begin{array}{l}\text { se (ICD9 410- } \\
4 \cdot 2 * * *(125) \\
(3 \cdot 5,5 \cdot 0) \\
3 \cdot 0 * * *(108) \\
(2 \cdot 5,3 \cdot 6)\end{array}$ & $\begin{array}{l}4): \\
4 \cdot 0^{* * *}(45) \\
(2 \cdot 9,5 \cdot 4) \\
2 \cdot 6^{* * *}(79) \\
(2 \cdot 1,3 \cdot 2)\end{array}$ & $\begin{array}{l}1 \cdot 0(18) \\
(0 \cdot 6,1 \cdot 5) \\
0 \cdot 7(11) \\
(0 \cdot 4,1 \cdot 3)\end{array}$ & $\begin{array}{l}1 \cdot 4(12) \\
(0 \cdot 8,2 \cdot 4) \\
1 \cdot 5(15) \\
(0 \cdot 9,2 \cdot 5)\end{array}$ \\
\hline $\begin{array}{l}\text { Stroke (ICD9 } 430-6 \\
45-64 \text { years } \\
(95 \% \text { CI) } \\
65+\text { years } \\
(95 \% \text { CI })\end{array}$ & $\begin{array}{l}38): \\
4 \cdot 1 * * *(25) \\
(2 \cdot 7,6 \cdot 2) \\
1 \cdot 8^{* *}(29) \\
(1 \cdot 3,2 \cdot 6)\end{array}$ & $\begin{array}{l}2 \cdot 6 * *(9) \\
(1 \cdot 4,5 \cdot 2) \\
1 \cdot 8 * * *(35) \\
(1 \cdot 3,2 \cdot 5)\end{array}$ & $\begin{array}{l}4 \cdot 0 * * *(15) \\
(2 \cdot 4,6 \cdot 7) \\
4 \cdot 1 * * *(27) \\
(2 \cdot 8,5 \cdot 9)\end{array}$ & $\begin{array}{l}2 \cdot 7^{*}(7) \\
(1 \cdot 3,5 \cdot 7) \\
3 \cdot 5 * * *(22) \\
(2 \cdot 3,5 \cdot 3)\end{array}$ \\
\hline
\end{tabular}

${ }^{*} \mathrm{p}<0.05,{ }^{* *} \mathrm{p}<0.01,{ }^{* * *} \mathrm{p}<0.001$.
Asians and African-Caribbeans than in people born in England and Wales (table 1). The largest ethnic differences were noted for heart disease deaths in South Asians and stroke deaths in African-Caribbeans.

In South Asians with diabetes, ischaemic heart disease death rates were approximately three times that of people born in England and Wales with diabetes. In contrast, AfricanCaribbean born men and women had stroke mortality rates which were 3.5-4 times that of the England and Wales population with diabetes, but mortality from heart disease, at least in African-Caribbean born men, was not significantly different to that of the general population with diabetes.

Relative age specific mortality rates show that these ethnic differences persist in younger and older age groups (table 2). However, in South Asians, ischaemic heart disease mortality is four times higher than for people born in England and Wales in the younger age group (45-64 years), and only three times higher in the older age group (65 years and above). This interaction between age group and ethnicity was statistically significant when formally tested: in men, the likelihood ratio statistic (LRS) on one degree of freedom was $6.00(p=0.01)$; in women, the LRS on one degree of freedom was $4.84(p=0.03)$. This interaction effect persisted for all cardiovascular disease in men (LRS 16.7, p<0.001) and women (LRS 11.5, $\mathrm{p}<0.001$ ), and for stroke in men (LRS 8.03, $\mathrm{p}=$ $0 \cdot 005)$. There were no significant interactions when African-Caribbeans were compared with people born in England and Wales.

Repeat analysis, using the unaged 1981 census denominator data, showed much larger relative ethnic differences in mortality, but the trends were the same.

\section{Discussion}

Ethnic differences in CVD mortality persist, and may be enhanced, in the presence of diabetes. We find that diabetes disproportionately increases the risk of ischaemic heart disease mortality in South Asians. In the general population, South Asian mortality rates from heart disease are only 1.5 times those of the general European population, ${ }^{11}$ but they seem to be three times higher when people with NIDDM are compared. Similarly, while mortality from stroke is twice that of the general population in African-Caribbeans, this risk is increased three to fourfold in people with diabetes. Ischaemic heart disease deaths in African-Caribbean born men with diabetes were not significantly higher than those of the general population. Although not statistically significant, there are indications from these data that in South Asians, men had a worse mortality experience than women, whilst in African-Caribbeans this sex ratio was reversed. Again, this reflects the experience of the general population. ${ }^{11}$

The ideal study design to examine this question would have been to perform a cohort study of people from different ethnic groups with NIDDM, but such a study would be time consuming and expensive. The United King- 
dom prospective diabetes study excluded those with a myocardial infarction in the previous year and other severe disease at baseline, and this may result in a biased sample if the two populations have different risks of cardiovascular disease ${ }^{17} \mathrm{~A}$ relatively quick, cheap and easy indicator of ethnic differences in diabetes related mortality is to use routinely available data, which act as a basis for more detailed, individual based studies.

Comparative data from other countries to which people of South Asian or African-Caribbean descent have migrated are scarce, but there are indications from the US that in older age groups, African Americans with diabetes have a lower risk of heart disease than US whites. ${ }^{18}$ An examination of death certificate data in Jamaica showed that about a third of all deaths in African-Caribbeans with diabetes were due to hypertensive, cerebrovascular and cardiovascular diseases combined. ${ }^{19} \mathrm{Un}$ fortunately, in this study, data for stroke and heart disease were not presented separately.

Country of birth is a valid proxy for ethnicity as migration to this country for both South Asians and African-Caribbeans occurred in the 1950 s and 60s, and few second generation migrants would have reached their 45 th birthday by $1985 .{ }^{20}$ Migrants from the Caribbean islands may be of South Asian rather than African-Caribbean descent, but this heterogeneity of the population under study would only serve to attenuate ethnic differences in cardiovascular mortality; true differences may be even greater than we show. There are concerns about the completeness of diabetes reporting on death certificates. ${ }^{14}$ This problem is partly addressed by use of multiple cause of death coding, but it is unlikely that incomplete data can explain such large ethnic differences in mortality, or the very different experience of African-Caribbeans and South Asians in their respective risks of CVD.

Ethnic differences in the prevalence of insulin resistance and its different effects on metabolism may account for these observed mortality differences. South Asians are more insulin resistant than the general population, and are resistant to insulin's glucose and lipid homeostatic effects. ${ }^{10}$ The resulting poor lipid profiles, with high triglyceride levels and low HDL cholesterol levels, may account for the high rates of heart disease in the general South Asian population, and for the increased risk of heart disease in those with NIDDM. In contrast, whilst African-Caribbeans have high insulin levels, and high rates of diabetes, lipid profiles are generally more favourable than that of the general population. ${ }^{21}$ These differences persist, and may be enhanced in the presence of glucose intolerance, ${ }^{22}$ so that African-Caribbeans with glucose intolerance still have relatively low rates of heart disease, ${ }^{18}$ and low triglyceride and high HDL levels compared with Europeans. The reasons for this are not known, but the cause may be a retention of sensitivity to the lipid homeostatic effects in African-Caribbeans. ${ }^{21}$
These findings add new insights to the investigation of the relationship between CVD and diabetes. They also have implications for care providers. Need for preventative care will increase as first generation migrants get older and second generation migrants enter the high risk age group. Young South Asians, especially men, with diabetes are at particular risk of heart disease, and should be targeted for control of obesity, particularly central obesity. ${ }^{10}$ In African-Caribbeans, the main problem is stroke, associated with high blood pressure. ${ }^{13}$ This emphasises the need for effective management of hypertension in African-Caribbeans. Despite high blood pressures, African-Caribbeans with diabetes are relatively protected from heart disease. The reasons for this relative protection remain to be established.

We would like to thank Tim Devis from the Health Statistics Division, Office of Population Censuses and Surveys for supplying the data to us, and Paul McKeigue for his helpfu comments on an earlier draft of this manuscript.

1 Klienman JC, Donahue RP, Harris MI, Finucane FF, Madans JH, Brock DB. Mortality among diabetics in a national sample. Am $\mathcal{f}$ Epidemiol 1988;128:389-401.

2 Kannel WB, McGee DL. Diabetes and cardiovascular disease. $\mathcal{F A M A}$ 1979;241:2035.

3 Stamler J, Vaccaro O, Neaton JD, Wentworth D. Diabetes, other risk factors, and 12-yr cardiovascular mortality for men screened in the multiple risk factor intervention trial. Diabetes Care 1993;16:434-44.

4 Krans HMJ, Porta M, Keen H. Diabetes care and research in Europe: the St Vincent declaration action programme. CopEurope: the St Vincent declaration action programme.

5 Kannel WB. Lipids, diabetes and coronary heart disease: insights from the Framingham Study. Am Heart f 1985; 110: $110-7$.

6 Wingard DL, Barrett-Connor E, Criqui MH, Suarez L. Clustering of heart disease risk factors in diabetic compared to nondiabetic adults. Am F Epidemiol 1983;117:19-26.

7 Barrett-Connor E, Wingard DL. Sex differential in ischemic heart disease mortality in diabetics: a prospective population-based study. Am $\mathcal{F}$ Epidemiol 1983;118:489-96.

8 Eschwege E, Richard JL, Thibult N, et al. Coronary heart disease mortality in relation with diabetes, blood glucose and plasma insulin levels: the Paris prospective study, ten years later. Horm Metab Res 1985;15(Suppl):41-6.

9 Goldschmid MG, Barrett-Connor E, Edelstein SL, Wingard DL, Cohn BA, Herman WH. Dysipidemia and ischemic DL, Cohn BA, Herman WH. Dysipidemia and ischemic heart disease mortality among men
betes. Circulation 1994;89:991-7.

10 Reaven GM. Role of insulin resistance in human disease. Diabetes 1988;37:1595-607.

11 OPCS. Mortality and geography: a review in the mid-1980s. The Registrar-General's decennial supplement for England and Wales, series DS no 9. London: HMSO, 1990

12 McKeigue PM, Shah B, Marmot MG. Relation of centra obesity and insulin resistance with high diabetes prevalence and cardiovascular risk in South Asians. Lancet 1991;337 382-6.

13 Chaturvedi N, McKeigue PM, Marmot MG. Resting and ambulatory blood pressure differences in Afro-Caribbeans and Europeans. Hypertension 1993;22:90-6.

14 Fuller JH, Elford J. Goldblatt P, Adelstien AM. Diabetes mortality: New light on an underestimated public health mortality: New light on an underestimate
problem. Diabetologia 1983;24:336-41.

15 Stephenson J, Swerdlow AJ, Devis T, Fuller JH. Recent trends in diabetes mortality in England and Wales. Diabetic Med 1992;9:417-21.

16 Epidemiological Resources. EGRET: epidemiological graphics, estimation and testing. Seattle, Washington: Epidemiological Resources, 1991; 1-305.

17 UK Prospective Diabetes Study Group. UK Prospective Diabetes Study Paper XII: Differences between Asian, Afro-Caribbean and White Caucasian Type 2 diabetic patients at diagnosis of diabetes. Diabetic Med 1994;11: 670-7.

18 DeStefano F, Newman J. Comparison of coronary hear disease mortality risk between black and white people with diabetes. Ethnic Diseases 1993;3:145-51.

19 Alleyne SI, Cruickshank JK, Golding AL, Morrison EY. Mortality from diabetes mellitus in Jamaica. Bull Pan Am Mealth Organ 1989;23:306-314.

20 Chaturvedi N, McKeigue PM. Methods for epidemiological surveys of ethnic minority groups. $\mathcal{F}$ Epidemiol Community Health 1994;48:107-11.

21 Chaturvedi N, McKeigue PM, Marmot MG. Relationship of glucose intolerance to coronary risk in Afro-Caribbean compared with Europeans. Diabetologia 1994;37:765-72.

22 Banerji MA, Lebovitz HE. Coronary heart disease risk factor profiles in black patients with non-insulin-dependent diabetes mellitus: paradoxic patterns. Am f Med 1991;91: 51-8. 